\title{
Novel sampling methods for monitoring Anopheles arabiensis from Eritrea
}

\author{
Jacques D Charlwood ${ }^{\text {Corresp., } 1,2}$, Amanuel Kidane Andegiorgish ${ }^{1,3}$, Yonatan Estifanos Asfaha ${ }^{1}$, Liya Tekle Weldu ${ }^{1}$, \\ Feven Petros $^{1}$, Lidia Legese ${ }^{1}$, Robel Afewerki ${ }^{1}$, Selam Mihreteab ${ }^{4}$, Corey LeClair ${ }^{5}$, Ayubo Kampango ${ }^{6,7}$ \\ 1 Epidemiology and Public Health, College of Health Sciences, Asmara, Eritrea \\ 2 Global Health and Tropical Medicine, Instituto de Higiene e Medicina Tropical, Lisbon, Portugal \\ 3 Department of Epidemiology and Biostatistics, Xi'an Jiaotong University, Shaanxi 710061, China \\ 4 Malaria Control Program, Asmara, Eritrea \\ 5 Medicins sans Frontiers, Bruxelles, Belgium \\ 6 Instituto Nacional de Saude, Maputo, Mozambique \\ 7 Department of Zoology and Entomology, University of Pretoria, Pretoria, South Africa \\ Corresponding Author: Jacques D Charlwood \\ Email address: jdcharlwood@gmail.com
}

Background: Studies comparing novel collection methods for host seeking and resting mosquitoes $A$. arabiensis were undertaken in a village in Eritrea. Techniques included an odor baited trap, a novel tent-trap, human landing collection and three methods of resting collection. A technique for the collection of mosquitoes exiting vegetation is also described. Pre-gravid rates were determined by dissection of host seeking insects and post-prandial egg development among insects collected resting. Results: Overall 5382 host-seeking, 2296 resting and $357 \mathrm{~A}$. arabiensis exiting vegetation were collected. The Furvela tent-trap was the most efficient, risk-free method for the collection of outdoor host-seeking insects, whilst the Suna trap was the least effective method. Mechanical aspirators (the CDC backpack or the Prokopack aspirator) were superior to manual aspiration in a dark shelter but there was no advantage over manual aspiration in a well-lit one. An estimated two-thirds of newly-emerged mosquitoes went through a pre-gravid phase, feeding twice before producing eggs. Mosquitoes completed gonotrophic development in a dark shelter but left a well-lit shelter soon after feeding. One blood-fed female marked in the village was recaptured two days after release exiting vegetation close to the oviposition site and another, shortly after oviposition, attempting to feed on a human host three days after release. Exit rates of males from vegetation peaked three minutes after the initial male had left. Unfed and gravid females exited approximately six minutes after the first males. Conclusions: Furvela tent-traps are suitable for the collection of outdoor biting $A$. arabiensis in Eritrea whilst the Prokopack sampler is the method of choice for the collection of resting insects. Constructing well-lit, rather than 
dark, animal shelters, may encourage otherwise endophilic mosquitoes to leave and so reduce their survival and hence their vectorial capacity. 
2 Novel sampling methods for monitoring Anopheles arabiensis from

3 Eritrea

4

5 J.D. Charlwood ${ }^{1,2}$, A.K. Andegiorgish ${ }^{1,3}$, Y. Asfaha ${ }^{1}$, L. Tekle Weldu ${ }^{1}$, F. Petros ${ }^{1}$, L.

6 Legese $^{1}$, R. Asfaha ${ }^{1}$, S. Mihreteab ${ }^{4}$, C. LeClair ${ }^{5}$ and A. Kampango 6

1- Epidemiology and Public Health, College of Health Sciences, Asmara, Eritrea

2- Global Health and Tropical Medicine, Instituto de Higiene e Medicina Tropical, Lisbon, Portugal

3- Department of Epidemiology and Biostatistics, Xi'an Jiaotong University, Shaanxi, China

4- Malaria Control Program, Asmara, Eritrea

5- Medecins sans Frontiers, Belgium.

6- Instituto Nacional de Saude, Maputo, Mozambique

7- Department of Zoology and Entomology, University of Pretoria, Pretoria, South Africa

e-mail: jdcharlwood@gmail.com

akidane2016@gmail.com

yonatanestifanos737@gmail.com

Robiyoasfaha16@gmail.com

lidiaghezae@gmail.com

smuqubay@gmail.com

corey leclair@hotmail.com

akampango@gmail.com

liya47tekle@gmail.com

Keywords

Anopheles arabiensis. Outdoor sampling. Tent-trap. Resting Behaviour. Control

\section{Abstract}

Background: Studies comparing novel collection methods for host seeking and resting

mosquitoes An. arabiensis were undertaken in a village in Eritrea. Techniques included an odour

baited trap, a novel tent-trap, human landing collection and three methods of resting collection.

A technique for the collection of mosquitoes exiting vegetation is described. Pre-gravid rates 
40 Results: Overall 5382 host-seeking, 2296 resting and 357 An. arabiensis exiting vegetation were

41 collected. The Furvela tent-trap was the most efficient, risk-free method for the collection of

42 outdoor host-seeking insects, whilst the Suna trap was the least effective method. Mechanical

43 aspirators (the CDC backpack or the Prokopack aspirator) were superior to manual aspiration in

44 a dark shed but there was no advantage over manual aspiration in a well-lit one. An estimated

45 two-thirds of newly-emerged mosquitoes went through a pre-gravid phase, feeding twice before

46 producing eggs. Mosquitoes completed gonotrophic development in a dark shed but left a lighter

47 shed soon after feeding. One blood-fed female marked in the village was recaptured two days

48 after release exiting vegetation close to the oviposition site and another shortly after oviposition

49 attempting to feed on a human host three days after release. Exit rates of males from vegetation

50 peaked three minutes after the initial male had left. Unfed and gravid females exited

51 approximately six minutes after the first males.

52

53 Conclusions: Furvela tent-traps are suitable for the collection of outdoor biting An. arabiensis in

54 Eritrea whilst the Prokopack sampler is the method of choice for the collection of resting insects.

55 Constructing well-lit, rather than dark, animal sheds, may encourage otherwise endophilic

56 mosquitoes to leave and so reduce their survival and hence their vectorial capacity.

57

58

59

60

61

62

63

\section{Introduction}

Efforts to eliminate malaria have increased in recent years and a number of countries are approaching a situation in which local cases of the disease no longer occur [WHO, 2017a]. To enter the elimination-phase the malaria burden should be reduced to an incidence rate of less than one per 1000 persons at risk [WHO, 2018]. In Eritrea the malaria burden has declined from 
64110 cases/1000 in 1998 to 6 cases/1000 in 2017 [WHO,2018], thus, approaching elimination. In

65 order to reach the target of elimination, however, residual malaria transmission must be

66 addressed. This includes monitoring of potential vectors and their control by application of

67 appropriate interventions in existing and newly-active foci [Killeen, 2104].

68 Given the substantial geographic heterogeneities in malaria burden, in Eritrea and elsewhere,

69 assessment of the bionomics of local anophelines is likely to require a range of bespoke

70 interventions for different populations. Anopheles arabiensis is the most common vector in east

71 Africa, to date it is the only recorded vector in Eritrea [Shililu et al., 2004 Wiebe et al., 2017],

72 and is noted for displaying ecological and behavioural plasticity such as readily biting animals or

73 humans, either indoors or outdoors [Sinka et al., 2010]. As such, control is challenging and its

74 importance as a vector is likely to increase in the future.

In 2017 larvae of An. arabiensis were found, on one occasion, on the outskirts of Asmara, the 77 capital, 2,200m above sea level in the Eritrean Highlands (JD Charlwood, unpublished data). At lower altitudes on the Escarpment mosquito populations are associated with streams, which exit

79 from small-scale dams used to create reservoirs that supply nearby villages with water during the

80 long dry season. Dams and streams are separated by several kilometres and, with typically

81 limited dispersal, mosquitoes are likely to occur in a metapopulation-patchwork of semi-isolated 82 sub-populations, whose ecology is defined as much by the environment as by intrinsic

83 characteristics [Verdonschot \& Besse-Lototoskaya, 2014]. A knowledge of mosquito bionomics

84 in such populations might help in the design of novel control techniques, especially those based 85 on environmental management rather than insecticides. 
86 Assessing outdoor mosquito activity is especially important because outdoor transmission may

87 maintain residual malaria once the major conventional techniques, indoor residual spraying with

88 insecticide (IRS) and use of LLINs, have been deployed [Killeen et al., 2013].

89 Traditionally the 'gold standard' for sampling outdoor biting mosquitoes has been the human

90 landing catch (HLC) in which collectors acting as bait catch mosquitoes attempting to feed on

91 their exposed lower legs [Silver, 2008]. Whilst this technique is likely to be the sample that best

92 reflects biting exposure outdoors there are a number of problems inherent to it. Human landing

93 catches require a considerable amount of supervision, are expensive to run, and, most

94 significantly, they often expose the collector to pathogen transmission [Achee et al., 2015].

95 These considerations have recently led the World Health Organization (WHO) to prioritize the

96 search for substitutes to HLC [WHO, 2017b] and whilst a number of alternatives have been

97 suggested, 'tent-traps', which catch blood-seeking mosquitoes, prior to biting appear particularly

98 promising [Charlwood et al., 2017]. Collectors are likely to differ in their efficiency, so that

99 numbers caught may be independent of the actual number biting. Humans produce a large range

100 of volatile chemicals [Penn et al., 2007] and vary in their attractiveness to mosquitoes. Individual

101 humans not only attract different numbers of mosquitoes but also different species [Knols et al.,

102 1995] so that it becomes difficult to extrapolate from the numbers collected to exposure to

103 disease. These difficulties are common to all techniques that involve humans as baits so

104 alternatives that do not require human involvement may be the most suitable sample. One such

105 sampling technique is the recently developed Suna trap which was both an effective sampling

106 device and control tool in Kenya [Homan et al., 2016].

107 
108 Outdoor biting insects may, nevertheless, rest inside houses or sheds either before or after

109 feeding, providing a target for control if their location can be identified [Killeen et al., 2016].

110 Suitable sampling methods for resting mosquitoes are, therefore, another priority. This may be

111 by collection of mosquitoes from houses, sheds or vegetation, e.g. using mechanical or manual

112 aspirators when the insects are resting during the day or when they leave their resting sites at

113 dusk.

114

115 A study designed to compare different collection techniques was, therefore, undertaken in

116 September-October 2016 in a village on the escarpment of the Eritrean Highlands. Two types of

117 tent-trap were compared with an odour baited trap (the SUNA trap [Homan et al., 2016]) and

118 HLC for the collection of mosquitoes' host-seeking outdoors whilst the CDC backpack aspirator

119 [Clark et al., 1994] and the Prokopack aspirator [Vazquez-Prokopec, 2009] were compared to

120 manual aspiration for the collection of those resting indoors. In addition, a novel method for the

121 sampling of insects leaving vegetation at dusk was developed.

122

123 Methods

124 Sample sites

125 The study took place between the $7^{\text {th }}$ and $23^{\text {rd }}$ of October 2016 in the environs of the village of

126 Adi Boskal (15 41' 41.67" N 38 38' 54.59” E) at an altitude of 1536m above sea level in Zoba

127 Anseba, Eritrea (Fig 1). The village comprises 25 stone-walled houses and is located on a steep

128 hillside $70 \mathrm{~m}$ above a field that abutted a stream; the outlet from the local micro-dam. At the time

129 of the survey no rain was recorded and the stream, in which large numbers of Anopheles larvae

130 were observed, was very slow flowing with filamentous algae. In addition to the houses there 
131 were two animal sheds in the village. At night five goats and a calf were kept in the first shed

132 (shed 1: $3.2 \mathrm{~m}$ length $\times 1.8 \mathrm{~m}$ width $\times 1.8 \mathrm{~m}$ height) and 10 goats and 5 sheep were kept in the

133 other ( $\operatorname{shed} 2: 3.8 \mathrm{~m} \times 3.1 \mathrm{~m} \times 1.6-1.8 \mathrm{~m}$ ). Close to shed 1, four cows and a donkey were kept in an

134 open-sided, thatched roof corral at night.

135 At other times of the year mosquito numbers are generally very low and in the 12 months prior to

136 the study there had been no cases of malaria from the village reported at the local hospital in the

137 nearby town of Elaberid.

138 Study design

139

140 A comparison between three methods of collecting post prandial resting mosquitoes were

141 conducted in the two animal sheds shown as red triangles in Figure 1 and five methods of

142 collecting host-seeking mosquitoes across a transect, shown as yellow circles in Fig 1, were

143 undertaken. To evaluate the performance of the different types of collection method a

144 randomised block experimental design was applied. As such, collection methods were randomly

145 assigned to sites (blocks) situated approximately 45 metres apart to avoid possible interference

146 between collection methods. Then, collectors were also randomly assigned to these locations to

147 perform either HLC catches or act as bait in tent-traps. Collection methods were rotated between

148 sites to account for any possible environmental heterogeneity on trap performance. Accordingly,

149 collectors were rotated between collection methods to reduce the influence of differential

150 attractiveness between collectors on mosquito catch. At each site collection were performed for 5

151 replicate-days.

152 A sample of mosquitoes exiting vegetation by the edge of the river valley below the village and

153 a sample from swarms observed over the river bed were also collected at sunset. 
155

156

157

158

159 Mosquitoes resting in the animal sheds were collected either with 1) a CDC-backpack aspirator

160 [Clark et al., 1994), 2) a home-made Prokopack aspirator [Vazquez-Prokopec, 2009] or 3) by

161 manual aspiration. The supplementary file 2 'Sampling routine' indicates the dates when the

162 different collection techniques were used in each shed. Removal sampling [Southwood, 1978]

163 was undertaken in order to determine if the different collection methods produced similar

164 population estimates.

165

166

167

168

169

170

171

172

173

174

175

176

177

178

179

180

181

Light levels inside the two sheds were measured using a Hand-held LX1010B light-meter

(Yingxinguang, Guandong, China) that registered down to 1 Lux.

\section{Host seeking mosquitoes}

The efficiency of the Suna trap was compared to both tent-traps and HLC in the field below the village, shown in Fig 1. The supplementary file 'Sampling routine' indicates the location on the transect and date when the different collection techniques were used. At the same time a sentinel tent-trap (with two doors and two traps attached) was run on a nightly basis in one corner of the field (shown as the white square in Fig 1).

\section{Landing collections}

Human landing collections (HLC) were performed by two teams of three people, in the field below the village, with each individual working a three or four-hour shift (19:00-23:00; 23:0003:00 and 03:00-06:00). Collectors, using a torch and an aspirator, caught mosquitoes as they attempted to feed on their exposed lower legs and feet. Collected mosquitoes were separated into 
182 four-hourly groups. When not working the collectors acted as bait in tent-traps. Thus, the

183 collectors from the earliest shift replaced the sleepers in the tents who worked the second shift

184 and they themselves replaced the sleepers in the other tents who undertook the last shift of

185 landing collection. The period and location during which the individual collectors worked was

186 alternated on different nights to reduce the influence of differential attractiveness on mosquito

187 catch.

188

189

190

191 Furvela tent-traps [Charlwood et al., 2017] were also used for the collection of outdoor biting

192 insects. Odour and exhaled gases from a host leave the tent through an approximately $8 \mathrm{~cm}$

193 opening, equivalent to the diameter of a CDC light-trap, in the door of the tent. A CDC trap

194 (without the light, lid or grid) is placed outside the tent, horizontally, 2 to $3 \mathrm{~cm}$ from this opening.

195 On approach to the opening the insects are sucked into the trap and held in a conical collection

196 bag.

197

198 In the second part of the study the BG-Lure (a synthetic lure, which, consisted of a mixture of

199 ammonia, L-lactic acid, and caproic acid, in undeclared proprietary concentrations (BioGents

$200 \mathrm{HmGb}$, Regensburg, Germany) designed to mimic human odour to attract mosquitoes [Homan et

201 al., 2016], was attached to the outside opening of the tent just below the CDC trap (Fig 2). This

202 facilitated the dispersion of volatiles from the lure. Collectors slept for two sequential nights in

203 the tents during this phase of the experiment. On one night, the lure was in use and on the other

204 there was no lure included. Tents were taken down and re-erected every day.

205

206

207

Furvela tent-trap Type II

Peer] reviewing PDF | (2020:09:52621:2:0:NEW 30 Mar 2021) 
208 A further comparison included a novel design for the attachment of the CDC trap to the tent. In 209 this case an A4 sized plywood board with an $8 \mathrm{~cm}$ diameter hole (the size of the internal diameter

210 of the CDC trap) was placed inside the tent at the opening. Two L-shaped clips were used to

211 attach the board to the trap with wing nuts. The clips were positioned at right angles to the tent

212 zip. In this way the size of the opening and the distance of the trap from the tent were more

213 easily standardized than in the basic tent-trap (Fig 3). A video describing the setting up of the

214 trap is available at https://youtu.be/3UCOhfPGgiw.

215

216

217

218

219

220

221

222

223

224

225

226

227

228

229

230

231

\section{Suna Trap}

The Suna trap (Biogents, Germany) (Fig 4) is a conical trap (52 cm high x $39 \mathrm{~cm}$ diameter) that has been used to control malaria vectors on Rusinga Island, western Kenya where it reduced malaria transmitted by An. funestus but was less effective against An. gambiae s.1. [Homan et al., 2016]. A $12 \mathrm{v}$ battery drives a fan that sucks mosquitoes up through a tube, with a $10 \mathrm{~cm}$ diameter opening, into a collection bag. Netting can be placed between the tube and the fan so that collected mosquitoes are not damaged when caught. A non-return gate that is activated when the fan is switched off, or when the tube is removed, means that under these circumstances, the tube acts as a collection cage. The remainder of the base of the trap is perforated with numerous small holes through which the odour from a BG-Lure that is placed inside the trap is blown.

There is also the possibility of adding carbon-dioxide to the trap via an external source connected with a tube to an outlet in the trap. In the trial in Rusinga Island 2-butanone was included as a substitute for carbon dioxide [Homan et al., 2016]. The lack of an effect against An. gambiae s.l. may have been due to the absence of carbon dioxide in the attractive mix. In the present experiment two traps were used. In one trap carbon dioxide was generated using a sugar and 
232 yeast mixture in 2L of water in a 5L plastic bottle [Smallegange et al., 2010] and in the other

233 carbon dioxide was not used.

234

235 The traps were suspended $70 \mathrm{~cm}$ above the ground using metal tripods, with the funnel opening

236 set $30 \mathrm{~cm}$ above the ground (Fig 4).

237

238

239

\section{Exit collections from vegetation}

240 Males and recently-emerged virgin females leave their diurnal resting site at dusk to mate, and

241 gravid females do so to oviposit. Endophilic mosquitoes can be collected at this time by placing a

242 netting barrier over the open door of houses [Charlwood, 2011]; a technique that was adapted here

243 for the collection of mosquitoes leaving their outdoor resting sites. In this case a double-sized (1.8

$244 \times 2.2 \mathrm{~m}$ ), rectangular mosquito net was mounted horizontally in front of an area in the vegetation

245 subjectively considered to be darker than the other vegetation bordering the stream, and the edges

246 sealed with sheets. A collector sat inside the net and caught mosquitoes as they emerged (Fig.5)

247 Collections were separated into three-minute intervals and light levels were recorded every minute.

248 At the same time swarming insects were observed by looking towards the lightest part of the sky

249 over the dry river bed in areas close to the exit site.

250

251

252

253

254

\section{Mosquito processing}

Insects from all collections were sexed, categorized to species or species group using the keys of Gillies and DeMeillon [1968] and Gillies and Coetzee [1987] and females sorted according to their abdominal condition into unfed, part-fed, engorged, semi-gravid and gravid according to Fig 6. The abdomens of a sample of blood-fed mosquitoes from the resting collections were squashed on 
256 filter paper and are available on request. A subsample of An. gambiae complex mosquitoes

257 collected were identified to species by PCR using the techniques of Scott et al [1993].

258 Resting collections

259

260 In order to determine the duration of resting inside the sheds after feeding, the proportion of

261 gravid: blood-fed females on days following three or more sequential days of prior collections

262 was compared to days when the sheds had been left undisturbed for a day previously. Anopheles

263 are generally gonotrophically concordant and each blood meal gives rise to complete egg batch.

264 Should blood-fed insects have remained in the shed then they would have become semi-gravid or

265 gravid by the second day, in which case the ratio of semi-gravid and gravid insects to the rest of

266 the population would increase; but if they normally left shortly after feeding then the proportion

267 of semi-gravid and gravid insects would not increase despite this respite in sampling.

268 Anopheles arabiensis may also take a pre-gravid blood meal during the first oviposition cycle

269 that is used for adult nutrition rather than egg development. By maintaining blood-fed females

270 alive for $24 \mathrm{hrs}$ it is possible to separate those females that will develop eggs and will become

271 gravid and those that will not develop eggs, despite being blood fed on collection. These females

272 are pre-gravid and are almost entirely newly emerged [Gillies, 1955]. The number of such pre-

273 gravid females is, therefore, one indicator of adult recruitment to the population, and their

274 relative frequency an indicator of mosquito survival rates [Charlwood et al., 2003]. On six days

275 engorged mosquitoes collected resting were kept in the insectary for $24 \mathrm{hrs}$ and the proportion

276 pre-gravid (i.e. the proportion that did not develop eggs) determined. Results were compared to

277 estimates obtained by dissection of host-seeking mosquitoes. In this case virgin females, with

278 undeveloped ovaries, that attempt to feed, will not develop eggs and so would go through a pre-

279 gravid phase.

Peer] reviewing PDF | (2020:09:52621:2:0:NEW 30 Mar 2021) 
281 In order to determine post-prandial behaviour a series of three capture-recapture experiments

282 using engorged mosquitoes from resting collections were performed. Engorged insects, collected

283 resting from shed 1 , were counted, dusted with fluorescent powder and released back into the

284 shed. Mosquitoes from all subsequent collections (resting, host-seeking and exiting vegetation)

285 were scanned with UV-light for colour which revealed previous marking.

286

287

288

289

290

291

292

293

294

295

296

297

298

299

300

301

302

303

304

\section{Host seeking collections}

Mosquitoes from the tent-trap collections were dissected for parity, sac-stage and mated status according to the schema outlined in Charlwood et al. [2003].

\section{Statistical analysis}

Mosquito density by trapping method, period and shed was expressed in terms of Williams geometric mean $\left(\mathrm{M}_{\mathrm{w}}\right)$. Williams means have been shown to be a robust measure of central tendency compared to arithmetic means, as they are less sensitive to both abundance and periodicity of insect occurrence [Williams, 1937, Haddow, 1954]. The absolute density of mosquitoes in each shed was estimated using the maximum weighted likelihood method of Zippin [1956, 1958] as modified by Carle and Strud [1978]. In this case the population size, $N$, is estimated as the smallest integer greater than the total catch, $T$, that satisfies the following inequality: $\left(\frac{N+1}{N-T+1}\right)\left(\frac{k N-M+T+0.5 K}{k N-M+1+0.5 k}\right) k \leq 1$, where $k$ is the total number of removal periods. The

parameter $M$ is estimated by the equation $M=\sum_{i=1}^{k}(k-i) c_{i}$, where $c_{i}$ is the number of individuals sampled.

Generalized Linear Multilevel Models (GLMMs) with negative binomial error distribution and log-link functions were applied to model the difference in sampling catches produced by the 
305 three resting collection methods, that is, Manual Aspirator, Backpack and Procopack. Collection

306 method (a three levels factor: Manual Aspirator, Backpack and Procopack), shed (a binary

307 factor: Shed 1 and Shed 2) and collection technique (a five-level factor: $1^{\text {st }}-5^{\text {th }}$ rounds) were

308 considered as fixed factors. To accommodate potential hierarchical (correlation) and explicit

309 nesting structure of repeated measurements across collectors and during the study period, as

310 evidenced by exploratory analysis, both collector and time (in days) effects were modelled as

311 crossed random factors. This allowed the performance of each collection method to vary among

312 collectors and days within sheds. Model fit was assessed by visual inspection of the graph of

313 standardized model residuals against fitted observations [Hartig, 2020]. The amount of variation

314 of mosquito counts explained by predictors was determined by both marginal and conditional

315 coefficients of determination $R^{2}$, proposed in Nakagawa \& Schielzeth [2013]. Additionally, Akaike

316 Information Criterion test (AICc) was applied to guide the selection of the best model fit. The

317 most parsimonious model (the one with the lowest AICc) was preferred among the others. Final

318 estimation of the mean and $95 \%$ Credible Interval bands (95\% CrI) of fixed effect coefficients

319 were obtained via simulations from posterior distribution of best model fit parameters. A total of

3202000 random simulations were performed using the function sim of the arm packages [Gelman \&

321 Yu-Sung, 2018]. The performance of the CDC Backpack Aspirator and Prokopack in relation to

322 Manual Aspiration was estimated in terms of Incidence Rate Ratio (IRR). The Tukey post-hoc

323 multiple comparisons test was applied to determine the significance of the difference between

324 main effect treatment levels and interacting effects levels. GLMM and post-hoc tests were

325 performed using the packages lme4 v.1.1-23 [40] and emmeans v.1.4.8 [Lenth, 2020], respectively.

326 Similarly, GLMMs was also applied to investigate the significance of the difference between 
327 mosquito catches obtained by Tent-traps and Suna trap. All the data processing tasks and

328 statistical analysis were performed using the $\mathrm{R}$ software version 4.0.2 [R Core team, 2020].

330 Ethical approval for the study was provided by the Research Ethical Clearance Committee of the 331 Asmara College of Health Sciences on the 18/09/2017.

332

333

334

335

336

337

338

339

340 341 study.

342

343

344

345

346

347

348

349

350

351

\section{Results}

Temperatures during the night dropped to a minimum of $11.8^{\circ} \mathrm{C}$ outdoors but were $4^{\circ} \mathrm{C}$ warmer inside the tents (minimum of $15.1^{\circ} \mathrm{C}$ inside the tents). All 37 An. gambiae s.l. from resting collections identified to species by PCR were An. arabiensis. Since this is the only member of the species complex to have ever been found in Eritrea [Shililu et al., 2004] we assume that this was the only species collected. A total of 5382 host seeking, 2296 resting and 357 An. arabiensis exiting vegetation were collected during the experiment. In addition, 1 male and 1 female $A n$. demellioni, 6 An. garnhami and 1 An. turkhudi were collected resting towards the end of the

Greatest numbers of host-seeking females were collected in the sentinel tent-trap run for 23 consecutive nights during the experiment (geometric mean of 162 per night $95 \%$ C.I. 117.13, 224.87). The majority of host-seeking parous mosquitoes had large follicular sacs, indicating a rapid return to host-seeking after oviposition [Charlwood et al., 2018]. Total numbers collected declined during the experiment whilst at the same time the parous rate among the 281 mosquitoes dissected [Charlwood et al., 2018] increased from 21\% to 56\% (Fig 7). Thus, there was a decline in output of newly emerged insects and the population was an ageing one.

Collections from 49 tent-traps, eight all night landing collections and 28 resting collections were positively correlated (Pearson's $r=0.64 n=5$, n.s, between tent and landing collections; $r=0.76 n$

Peer) reviewing PDF | (2020:09:52621:2:0:NEW 30 Mar 2021) 
$352=5, \mathrm{P}=0.05$ between tent and resting collections; $\mathrm{r}=0.97, \mathrm{n}=12, \mathrm{P}=>0.01$ between landing and

353 resting collections). The data from all collections is provided in the supplementary file 3 .

354

355 Resting collections

356 Mosquito counts by collection method

357 Shed 1 was darker than shed 2 ( 20 vs 40 Lux measured at 09:00). Temperature extremes were

358 also greater in the more open Shed 2 (maximum and minimum temperatures recorded close to

359 the roof of the sheds over $24 \mathrm{hrs}$ being $46.7^{\circ} \mathrm{C}$ and $18.2^{\circ} \mathrm{C}$ in Shed 2 compared to $39.6^{\circ} \mathrm{C}$ and

$36017.2{ }^{\circ} \mathrm{C}$ in Shed 1). A total of 1561 and 735 female and 93 and 19 male An. arabiensis were

361 collected from Shed 1 and Shed 2, respectively from 134 rounds of sampling. The estimated

362 abundance of mosquitoes in the two sheds according to the different methods of collection with

363 their 95\% confidence intervals are shown in Table 1.

364 Relatively high mosquito counts were obtained from Shed 1 using either the Backpack or

365 Procopack compared to manual aspiration (Table 1). Manual aspiration produced a total of 198

366 mosquitoes (Shed 1) and 208 mosquitoes (Shed 2), Backpack (723 vs. 157) and Procopack (640

367 vs. 370). Results of estimation of total abundance of indoor resting mosquito population by

368 removal test (Table 1) suggest that manual aspiration underestimated density in both sheds. On

369 the other hand, the Backpack may have underestimated the population abundance at Shed 2

370 compared to manual aspirator and, especially, Procopack. The overall estimate of total

371 abundance $( \pm 95 \% \mathrm{CI})$ by combining catches from all the three methods were $1580(1567-1585)$

372 and $750(738-754)$ from shed 1 and shed 2 , respectively. The probability of capture was 0.603

$373(0.581-0.624)$ and $0.566(0.534-0.598)$. 


\section{Sampling regime and collection performance}

376

377

378

379

380

381

382

383

384

385

386

387

388

389

390

391

392

393

394

395

396

397

398

399

There was a sharp reduction in the number of mosquitoes collected after the first sampling round, irrespective of collection method or shed but the three methods produced similar numbers caught after the second round of collection (Fig 8). The distribution of mosquito counts by the three methods were heavily (right) skewed (supplementary file 4). Further exploratory analysis suggested that the counts could plausibly be described by a negative binomial distribution function. Additionally, since collections were repeatedly performed by the same individuals at the same sheds (shed 1 and shed 2) over the study period some amount of dependency (correlation structure) between observations was introduced (supplementary file 4).

The best model fit of sampling method performance $(\mathrm{AICc}=852.2)$ was one that included collection method and shed as main effects factors and an interaction effect between collection methods and sampling regime. Collectors and day of collection were considered as random factors. Both fixed and random factors explained $86.6 \%$ of the variability in mosquito counts (Figure 9). Results of mosquito Incidence Rate Risks (IRR \pm 95CrI) indicate that a mosquito was, respectively, $1.45(0.89-2.32)$ and $1.83(1.17-2.29)$ more likely to be sampled by CDC Backpack and Prokopack compared to manual aspiration. However, the difference was statistically significant only between manual aspiration vs Prokopack. The results also showed that the likelihood of collecting any mosquito varied significantly between sheds; that is, the chance of collecting at Shed 2 was $41.6 \%$ lower compared to Shed 1 . There were also significant interaction effects between collection methods and sampling regimes.

There was a significant difference between the relative proportions of An. arabiensis females in different abdominal stages collected from shed 1 and shed 2 on the days when no collections

Peer] reviewing PDF | (2020:09:52621:2:0:NEW 30 Mar 2021) 
400 were conducted the previous day ( $X^{2}$ with Yates correction 23. 5, $\left.p<0.00002\right)$. (Table 2). On

401 the 10 days when resting collections had been conducted the previous day the relative

402 proportions of An. arabiensis by abdominal stage from either shed were similar $X^{2}$ with Yates

403 correction $=2.3963, p=0.12$ ) but the proportion of semi-gravid and gravid An. arabiensis

404 females collected from Shed 1 were significantly higher than Shed 2, the lighter shed, following

405 days in which no previous collections had been undertaken $\left(X^{2}\right.$ with Yates correction is $7.3493, p$

$406=0.0067)$. The number of females collected from Shed 2 was not significantly different from

407 numbers collected following days where previous collections had been undertaken $(\mathrm{DRR}=0.84$,

408 95\% CI: $0.56-1.26, \mathrm{P}=0.41)$.

409 Pre-gravid rates

410 Seventy-two (35\%) of the 204 engorged mosquitoes collected resting and kept in the insectary

411 for $24 \mathrm{hrs}$ failed to develop eggs, and so were pre-gravid. This proportion was similar to the 86

$412(31 \%)$ of the 281 dissected insects that were virgins $\left(X^{2}=1.6, \mathrm{P}=0.21\right)$. Fifty-one $(37 \%)$ of the

413 recently emerged insects dissected had a mating plug. These insects may develop eggs after a full

414 blood meal and implies that at least two thirds of newly emerged insects went through a pre-

415 gravid stage.

416 Exit collections

417

418 Males started to exit the vegetation when light levels fell to approximately 500 Lux each day

$419($ mean $=506$ Lux; standard deviation = 80 Lux; range 373-610 Lux $)$. Peak exit rates of males

420 occurred three minutes after the initial mosquito was collected. Both unfed and gravid females

421 were collected leaving the vegetation a few minutes after the males (Figure 10). One of the 13

422 gravid females collected had been and marked 2 days earlier and released, engorged, back into

423 Shed 1.

Peer] reviewing PDF | (2020:09:52621:2:0:NEW 30 Mar 2021) 
424

425

426

427

428

429

430

431

433

434

436

437

438

439

440

441

442

443

444

445

446

447

448

449

\section{Performance of host-seeking sampling methods}

The number collected in the HLC decreased with time during the night as did the temperature.

The geometric mean number per night in the HLC was 35.02 (s.d. 12.9). After eight nights of collection a total of 40 An. arabiensis (mean of 5 per night 95\% C.I. 1.18- 8.82) were collected in the Suna trap with carbon dioxide and only 10 were collected when the trap was used without carbon dioxide (mean 1.25 per night, 95\% C.I. 0-3.6) (Table 3). The Suna trap also failed to collect any mosquitoes when it (with added carbon dioxide) was moved alongside a likely flight path of the mosquitoes by the vegetation $15 \mathrm{~m}$ from the sentinel tent-trap, or close to the base of the hill leading to the village. Furvela traps type I and type II collected, respectively, 6.23 (4.90 7.97) and $4.63(3.42-7.96)$ significantly more mosquitoes than did the HLC. Both types of Furvela tent traps collected relatively similar numbers of mosquito (Incidence Ratio $=1.36$; $95 \% \mathrm{CI}=0.917-2.013)($ Figure 11).

A previously marked blood-fed mosquito, was recaptured (with notably large follicular sacs), host-seeking in the sentinel tent-trap, two days after release in Shed 1.

The addition of the lure to the tent-trap, either in the sentinel trap or the experimental tents, did not result in an increase in the number of mosquitoes collected $\left(t^{7}=0.28, \mathrm{P}=0.79\right.$ for sentinel tent trap; $\mathrm{t}^{7}=0.48, \mathrm{P}=0.64$ for experimental tents).

\section{Discussion}

Monitoring outdoor biting and resting malaria vectors has assumed a greater importance as a result of worldwide efforts to eliminate the disease [WHO, 2018]. Previous work has highlighted the potential importance of outdoor exposure to An. arabiensis in Eritrea [Shililu et al., 2004]. 
450 Two alternatives were tested to HLC for the monitoring of outdoor biting mosquitoes in Adi

451 Boskal, the Suna trap and the Furvela tent-trap. In comparisons between an earlier version of the

452 Furvela trap and HLC, where An. gambiae was the principle vector collected, the methods were

453 similar at low densities but at higher densities HLC was considered to be more efficient [Govella

454 et al., 2009]. Nevertheless, several thousand mosquitoes have been caught in a night with a

455 single trap [Charlwood et al., 2011, 2012, 2013].

456 The Suna trap caught very small numbers of An. arabiensis compared to the other collection

457 methods. Cribillier et al., [2020] have recently shown that adding heat to a trap increases its

458 efficiency. Thus, one reason why the Suna trap failed to collect mosquitoes may be because the

459 trap did not have a sufficient 'heat signature' that might otherwise aid mosquitoes in location

460 when in close proximity to potential hosts. It is also possible that the lure used failed to elicit a

461 response from the mosquito. The fact that numbers were not affected in the sentinel trap when a

462 lure was attached to the opening and the relative inefficiency of the trap against An. gambiae s.l.

463 in Kenya [Homan et al., 2016] and Tanzania [Cribillier et al., 2020] indicates that this might be

464 the case. On the other hand, our results indicate that Furvela tent-traps are a suitable, indeed a

465 more efficient, alternative to HLC for the collection of outdoor biting An. arabiensis in this area.

466 At the temperatures experienced, collectors' legs became cold and may also have not given off

467 heat cues that assist host location. It is therefore possible that the difference between tent-trap

468 collections and HLC may be less apparent at warmer temperatures. Nevertheless, there remain

469 considerable advantages in using tent-traps, not the least of which are getting a good night's

470 sleep, not being exposed to pathogens and having a uniform collection efficiency between tents.

471 The method used to attach the CDC-trap to the tent, however, did not significantly affect the

472 number of An. arabiensis collected. 
473 In the present experiments the sentinel trap caught more than twice as many mosquitoes as the

474 other tents. There are a number of possible reasons for this: the odour of the host in the tent

475 (JDC) whilst being unappealing to humans may have been particularly attractive to mosquitoes;

476 the tent was larger than the other tents and the enhanced visual profile may have attracted more

477 mosquitoes [Hawkes \& Gibson, 2016]. Because mosquitoes tend to fly along the edge of

478 vegetation [Charlwood and Wilkes, 1981] those that rested in vegetation close to the river, or

479 that oviposited prior to host seeking may have been funnelled through the opening where the

480 sentinel trap was located. Thus, the trap may have sampled from a more concentrated population

481 than the other traps and so caught more mosquitoes as a result. Setting up tent-traps in such

482 locations may enhance collections, which is especially useful at low mosquito population

483 densities.

484

485 The collection of resting females also forms an important component of vector monitoring. The

486 results of sequential sampling using either the CDC-backpack aspirator, a Prokopack aspirator,

487 or manual aspiration were equivocal. For removal sampling to function adequately a number of

488 assumptions must be met: the catching procedure must not affect the probability of an animal

489 being caught; the population must remain stable during the catching period, sampling effort must

490 be the same in each round of collection and, most importantly, the chance of being caught must

491 be equal for all animals. A relatively large proportion of the population must also be caught to

492 obtain reasonably precise estimates. Numbers collected on each trapping interval must also

493 decline for estimates to be meaningful [Southwood, 1978]. Whilst we were unable to estimate

494 total numbers in the sheds on all but a few occasions our results indicate that between a quarter

495 and two thirds of the total sample was obtained during the initial round of collection depending

496 on the shed and method used (Table 1). Thus, a single round of collection from an indoor resting 
497 site is a suitable sampling procedure. It being better to sample five sheds, once than one shed five 498 times.

499

500 The number of mosquitoes collected by manual aspiration, especially in Shed 1 was lower than

501 the other methods. This is probably because not only was the shed dark but there were many hard 502 to see hiding places due to the shed walls being made of stones. It was not easy to illuminate 503 these hiding places with a torch. These considerations did not affect collection by mechanical 504 aspirator. In Tanzania, Maia et al [2011] found that CDC backpack and Prokopack aspirators 505 were equivalent in efficiency for collecting mosquitoes in general, but that the Prokopack was 506 easier to use and there was increased consistency across the numbers of mosquitoes collected by 507 four different collectors operating the Prokopack compared with the CDC-BP. Also, in Tanzania 508 the Prokopack was considered to be a better method for collection of resting insects than manual 509 aspiration [Charlwood et al., 2018b]. It is now the method of choice for such samples.

511 The blood-fed An. arabiensis released in the animal shed in the middle of the village and

512 recaptured gravid two days later exiting vegetation close to the oviposition site at dusk indicates

513 that females probably arrive there half-gravid. Seeking a resting site close to the oviposition site

514 when half gravid makes sense if the oviposition site is some distance from the (indoor) feeding

515 site. It is undertaken when the insect still may have the ability to use energy from the blood meal

516 for flight (although by being outside nectar sources may be available) and means that the insects

517 can start hunting early in the night and shortly after oviposition. They will not have used energy

518 unnecessarily flying from the village to the oviposition site before starting to hunt, which they

519 did shortly after oviposition, as shown by the high proportion of dissected females with large 
520 follicular sacs [Charlwood et al., 2018a], including one marked and released in the same shed

521 two days previously. The marked mosquito collected from the tent-trap had presumably fed on a

522 non-human host prior to release. These results emphasise the rapid gonotrophic cycle in this

523 species and also suggests a lack of 'host fidelity' in the mosquito.

524

525 Male arabiensis in Adi Boskal appeared to spend much of their lives in vegetation close to the 526 emergence site. It was from here that they were collected at dusk. Emergence from vegetation

527 was, as expected, related to illumination and, as expected, males left before the females. Most of

528 the females collected exiting vegetation were unfed. Such females are largely newly emerged

529 virgins who would presumably mate in swarms, which were seen at this time in the river bed,

530 before ascending the hill to the village for their first blood meal. How, or where, pre-gravid

531 virgin females, who feed in the village, mate remains unknown. Less than $5 \%$ of the insects

532 collected from the animal sheds were males and alternative sites for males to rest were not

533 obvious. Unfortunately searching for and monitoring of swarms in the village was not

534 undertaken. Similarly, the question of how the mosquito (and the other anophelines collected)

535 maintain themselves at times of low population density is not known and whether they do form

536 part of a meta-population (which implies occasional extinction) remains moot.

537

538

539

540

541 the previous day compared to the lighter shed. The absence of any difference between days when

542 sampling had been curtailed on the previous day in the lighter shed indicates that the insects were

543 leaving before they became gravid. This implies that the insects had left the lighter shed to rest

PeerJ reviewing PDF | (2020:09:52621:2:0:NEW 30 Mar 2021) 
544 outside. Resting outside shortly after feeding may have a significant mortality risk for

545 mosquitoes (and may be one reason why species that rest inside houses are better vectors than

546 those that rest outdoors) [Gillies, 1954b]. Constructing well-lit, rather than dark, animal sheds,

547 may encourage otherwise endophilic mosquitoes to leave and so reduce their survival and hence

548 reduce malaria transmission.

549

550 Given that the population was not stable during the study, but rather suffered a decline in output,

551 estimation of survival by parous rate determination was not possible. The data was also

552 insufficient to determine survival rates by time-series analysis. Nevertheless, just over a third of

553 all the insects from the resting collections were pre-gravid whilst almost half the mosquitoes

554 collected from the tent-trap had stage I ovaries, suggesting that they were also pre-gravid

555 females. Thus, newly emerged mosquitoes comprised a large proportion of the collections,

556 indicating a relatively low survival rate in the mosquito. The higher proportion of mosquitoes

557 that were considered to be pre-gravid by dissection compared to those from resting collections

558 may reflect mortality amongst such females before they could obtain a blood meal (as appears to

559 happen with young An. coluzzii from São Tomé [Charlwood et al., 2003]. All older females

560 were gonotrophically concordant and took two/three days per oviposition cycle.

561

562 Owing to the low night-time temperatures in Adi Boskal, people enter their houses early in the

563 evening. Making sure that houses are mosquito-proof and that villagers have access to LLINs

564 should help protect them from malaria. Whether anything other than current control techniques

565 (LLINs over all beds in the village) needs to be used in Adi Boskal is moot. There had been no

566 cases of malaria reported from Adi Boskal in the previous year and so the village would seem to

567 be a case of anophelism sans malaria. Although it is not certain that the mosquito provides any 
568 benefit to local ecosystems it may do so. Treating cattle or spraying the shed with insecticide

569 would also, perhaps, enhance the development of resistance in the mosquito and waste precious

570 resources.

571 Conclusions

572

573 At the time of the study, although it would readily bite humans if they were available, the

574 Anopheles arabiensis population from Adi Boskal was apparently a largely zoophagic one. Most

575 of the newly emerged female mosquitoes went through a pre-gravid phase after which they

576 became gonotrophically concordant with a rapid gonotrophic cycle. A proportion of the semi-

577 gravid and gravid insects would leave their resting site to rest in vegetation close to the stream

578 below the village prior to oviposition. Male mosquitoes rested in vegetation and swarmed close

579 to the stream below the village. Furvela tent-traps set up in areas where there may be a flyway.

580 are a suitable alternative to human landing catches for the collection of outdoor biting $A n$.

581 arabiensis whilst the Prokopack mechanical aspirator is the method of choice for the collection

582 of resting insects. Constructing well-lit, rather than dark, animal sheds, may encourage otherwise

583 endophilic mosquitoes to leave and so reduce their survival and hence their vectorial capacity.

584 Availability of data and materials

585

586 The data file associated with the work described here is available as a supplementary file 3 (Adi

587 Boskal collections.xls). The analysis file is also available as a supplementary file 4 (Analysis)

588

589 Abbreviations

590 CDC Centres for Disease Control

591 HLC Human Landing Collection

592 IRS Indoor Residual Spray 
593

594

595

596

597

598

599

600

601

602

603

604

605

606

607

608

609

610

611

612

613

614

615

616

617

618

619

620

621

622

623

624

625

626

627

628

629

630

LLIN Long Lasting Insecticide-treated Net

WHO World Health Organization

\section{References}

Achee NL, Youngblood L, Bangs MJ, Lavery JV, James S. 2015. Considerations for the use of human participants in vector biology research: a tool for investigators and regulators. Vector Borne Zoonotic Disease 15: 89-102.

Carle FL, Strub MR. 1978. A new method for estimating population size from removal data. Biometrics 34: 621-630.

Charlwood JD. 2011. Studies on the biology of male Anopheles gambiae Giles and Anopheles funestus Giles from southern Mozambique. Journal of Vector Ecology 36: 382-394.

Charlwood JD, Macia GA, Manhaca M, Sousa B, Cuamba N, Bragança M. 2013. Population dynamics and spatial structure of human-biting mosquitoes, inside and outside of houses, in the Chockwe irrigation scheme, southern Mozambique. Geospatial Health. 7: 309-320.

Charlwood JD, Pinto J, Sousa CA, Ferreira C, Petrarca V, do Rosario VE. 2003, 'A mate or a meal' - Pre-gravid behaviour of female Anopheles gambiae from the islands of São Tomé and Príncipe, West Africa. Malaria Journal 2: Article 9

Charlwood JD, Rowland M, Protopopoff N, Le Clair C. 2017. The Furvela tent-trap Mk 1.1 for the collection of outdoor biting mosquitoes. PeerJ. 5: Article 3848

Charlwood JD, Protopopoff N, Rowland M, LeClair C. 2018b. Studies on the resting and feeding behaviour of Anopheles gambiae and An. arabiensis from Muleba District, North-eastern Tanzania. Medical and Veterinary Entomology.

Charlwood JD, Tomás EVE, Andegiorgish A, Mihreteab S, Le Clair C. 2018a. 'We like it wet': a comparison between dissection techniques for the assessment of parity in Anopheles arabiensis and determination of sac stage in mosquitoes alive or dead on collection. PeerJ 5: Article 155

Charlwood JD, Tomás EVE, Egyir-Yawson A, Kampango A, Pitts RJ. 2012. Feeding frequency and survival of Anopheles gambiae from a rice growing area of Ghana. Medical and Veterinary Entomology. 26: 263-70.

Charlwood JD, Tomás EVE, Salgueiro P, Egyir-Yawson A, Pitts RJ, Pinto J. 2011. Studies on the behaviour of peridomestic and endophagic M form Anopheles gambiae from a rice growing area of Ghana. Bulletin of Entomological Research 101: 533-539.

Charlwood JD, Wilkes TJ. 1981. Observations on the biting activity of Anopheles triannulatus bachmanni from the Mato Grosso, Brazil. Acta Amazonica 11: 411-413. 
631

632

633

634

635

636

637

638

639

640

641

642

643

644

645

646

647

648

649

650

651

652

653

654

655

656

657

658

659

660

661

662

663

664

665

666

667

668

669

670

671

672

673

Clark GG, Seda H, Gubler DJ. 1994. Use of the "CDC backpack aspirator" for surveillance of Aedes aegypti in San Juan, Puerto Rico. Journal of the American Mosquito Control Association 10: 119-124.

Cribellier A, Spitzen J, Fairbairn H, van de Geer C, van Leeuwen JL, Muijres FT. 2020. Lure, retain, and catch malaria mosquitoes. How heat and humidity improve odour-baited trap performance. Malar J 19, 357 https://doi.org/10.1186/s12936-020-03403-5

Gelman A, Yu-Sung S. 2018. arm: Data Analysis Using Regression and Multilevel/Hierarchical Models. $R$ package version 110-111.

Gillies MT, Coetzee MMT. 1987. A supplement to the anophelinae of Africa south of the Sahara (Afrotropical Region). Johannesburg: South African Institute for Medical Research. 143pp.

Gillies MT, De Meillon B. 1968. The Anophelinae of Africa south of the Sahara (Ethiopian zoogeographical region). Johannesburg: South African Institute for Medical Research. 343pp

Gillies MT. 1954. Studies in house leaving and outside resting of Anopheles gambiae Giles and Anopheles funestus Giles in East Africa. 2. The exodus from houses and the house resting population. Bulletin of Entomological Research 45: 375-387.

Gillies MT. 1955. The recognition of age-groups within populations of Anopheles gambiae by the pre-gravid rate and the sporozoite rate. Annals of Tropical Medicine \& Parasitology 48: 58-74.

Gillies MT, Hamon J, Davidson G, de Meillon B, Mattingly PF. 1961. A practical guide for malaria entomologist in the African region of WHO. WHO, Geneva. 276pp

Govella NJ, Chaki PP, Geissbuehler Y, Kannady K. Okumu F.O., Charlwood J.D., Anderson R. A., Killeen G. F. 2009. A new tent trap for sampling exophagic and endophagic members of the Anopheles gambiae complex. Malaria Journal 8: Article 8.

Haddow AJ. 1954. Studies of the biting-habits of African mosquitos. An appraisal of methods employed, with special reference to the twenty-four-hour catch. Bulletin of Entomological Research 45: 199-242.

Hartig F. 2020. DHARMa: Residual Diagnostics for Hierarchical (Multi-Level / Mixed) Regression Models. $R$ package version 0320

Hawkes F, Gibson G. 2016. Seeing is believing: the nocturnal malarial mosquito Anopheles coluzzii responds to visual host-cues when odour indicates a host is nearby. Parasites \& Vectors. 9:320.

Homan T, Hiscox A, Mweresa CK, Masiga D, Mukamba WR, OriaP, Maire N, di Pasquale A, Silkey M, Alaii J, Bousema T, Leeuwis C, Smith TA, Takken W. 2016. The effect of mass mosquito trapping on malaria transmission and disease burden (SolarMal): a stepped-wedge clusterrandomised trial. Lancet 6736: 30445-30447.

Peer] reviewing PDF | (2020:09:52621:2:0:NEW 30 Mar 2021) 
674

675

676

677

678

679

680

681

682

683

684

685

686

687

688

689

690

691

692

693

694

695

696

697

698

699

700

701

702

703

704

705

706

707

708

709

710

711

712

713

714

715

Killeen GF, Govella NJ, Lwetoijera DW, Okumu FO. 2016. Most outdoor malaria transmission by behaviourally resistant Anopheles arabiensis is mediated by mosquitoes that have previously been inside houses. Malaria Journal 15: Article 225

Killeen GF, Seyoum A, Sikaala C, , Zomboko AS, Gimnig JE, Govella NJ, White MT. 2013. Eliminating malaria vectors. Parasites \& Vectors. 6: Article 172

Killeen GF. 2014. Characterizing, controlling and eliminating residual malaria transmission. Malaria Journal 13: Article330

Knols BGJ, Takken W, Charlwood JD, De Jong R. 1995. Species-specific attraction of Anopheles mosquitoes (Diptera, Culicidae) to different humans in South-East Tanzania. Proceedings of Experimental and Applied Entomolgy (N.E.V.) Amsterdam. 6: 201-206.

Lenth R. 2020. emmeans: Estimated Marginal Means, aka Least-Squares Means. R package version 1.4.8; https://CRAN.R-project.org/package=emmeans

Maia MF, Robinson A, John A, Mgando J. Simfukwe E, Moore SJ. 2011. Comparison of the CDC backpack aspirator and the Prokopack aspirator for sampling indoor- and outdoor-resting mosquitoes in southern Tanzania. Parasites \& Vectors 4: Article 124

Nakagawa S, Schielzeth H. 2013. A general and simple method for obtaining R2 from generalized linear mixed-effects models. Methods in Ecology and Evolution 4: 133-142.

Penn DJ, Oberzaucher E, Grammer K, Fischer G, Soini HA, Wiesler D, Novotny MV, Dixon SJ, Xu Y, Brereton RG. 2007. Individual and gender fingerprints in human body odour. Journal of the Royal Society Interface. 4: 331-340.

R Core Team. 2020. R: A language and environment for statistical computing. Vienna, Austria: R Foundation for Statistical Computing

Scott JA, Brogdon WG, Collins FH. 1993. Identification of single specimens of the Anopheles gambiae complex by the polymerase chain reaction. American Journal of Tropical Medicine \& Hygiene 49: 520-529.

Shililu J, Ghebremeskel T, Seulu F, Mengistu S, Fekadu H, Zerom M, Asmelash GE, Sintasath D, Mbogo C, Githure J, Brantly E, Beier JC, Novak RJ. 2004. Seasonal abundance, vector behavior, and malaria parasite transmission in Eritrea. Journal of the American Mosquito Control Association 20:155-64.

Silver JB. 2008. Mosquito ecology, field sampling methods. Dordrecht: Springer. 1477pp.

Sinka ME, Bangs MJ, Manguin S, Coetzee M, Mbogo CM, Hemingway J, Patil AP, Temperley WH, Gething PW, Kabaria CW, Okara RM, van Boeckel T, Godfray HCJ, Harbach RE, Hay SI. 2010. The dominant Anopheles vectors of human malaria in Africa, Europe and the Middle East: occurrence data, distribution maps and bionomic précis. Parasites \& Vectors. 3: Article 117

Peer) reviewing PDF | (2020:09:52621:2:0:NEW 30 Mar 2021) 
716

717

718

719

720

721

722

723

724

725

726

727

728

729

730

731

732

733

734

735

736

737

738

739

740

741

742

743

744

745

746

747

748

749

750

751

752

753

754

755

756

Smallegange RC, Schmied WH, van Roey KJ, Verhulst NO. Spitzen J, Mukabana WR, Takken W. 2010. Sugar-fermenting yeast as an organic source of carbon dioxide to attract the malaria mosquito Anopheles gambiae. Malaria Journal 9: Article 292

Southwood TRE. 1978. Ecological methods: with particular reference to the study of insect populations. Chapman \& Hall. 524pp

Vazquez-Prokopec G. 2009. A New, cost-effective, battery-powered aspirator for adult mosquito collections. Journal of Medical Entomology 46: 1256-1259.

Verdonschot PFM, Besse-Lototoskaya AA. 2014. Flight distance of mosquitoes (Culicidae): A metadata analysis to support the management of barrier zones around rewetted and newly constructed wetlands. Limnologica. 45: 69-79.

Wiebe A, Longbottom J, Gleave K, Sinka ME, Massey NC, Cameron E, Bhatt S, Gething PW, Hemingway J, Smith DL, Coleman M, Moyes CL. 2017. Geographical distributions of African malaria vector sibling species and evidence for insecticide resistance. Malaria Journal 16: Article 85

Williams CB. 1937. The use of logarithms in the interpretation of certain entomological problems. Annals of Applied Biology 24: 404-414.

World Health Organization. 2017a. Global vector control response -2030. 2017. Geneva: World Health Organization.

World Health Organisation. 2017b. Ethical issues associated with vector-borne diseases. Geneva: World Health Organisation.

World Health Organization: World malaria report. 2018. Geneva: World Health Organization.

Zippin C. 1956. An evaluation of the removal method of estimating animal populations. Biometrics 12: $163-89$.

Zippin C. 1958. The removal method of population estimation. Journal of Wildlife Management 22: 82-90.

\section{Acknowledgements}

We would like to thank the students of the College of Health Sciences, especially Kokob Tesfay, for their assistance during the experiments. We would also like to thank the editor and reviewers for their perceptive comments which helped us to considerably improve the manuscript. 


\section{Figure 1}

Map of the study area (c) 2019 Google Image Landsat/Copernicus

The village of Adi Boskal, Anseba Zoba, Eritrea, showing the location of the outdoor trapping sites (yellow circles with numbers representing catch number), the sentinel tent-trap (white square) and the two sheds used for the collection of resting insects (red triangles). Also shown is the location where the exit collections took place (c) 2019 Google Image Landsat/Copernicus

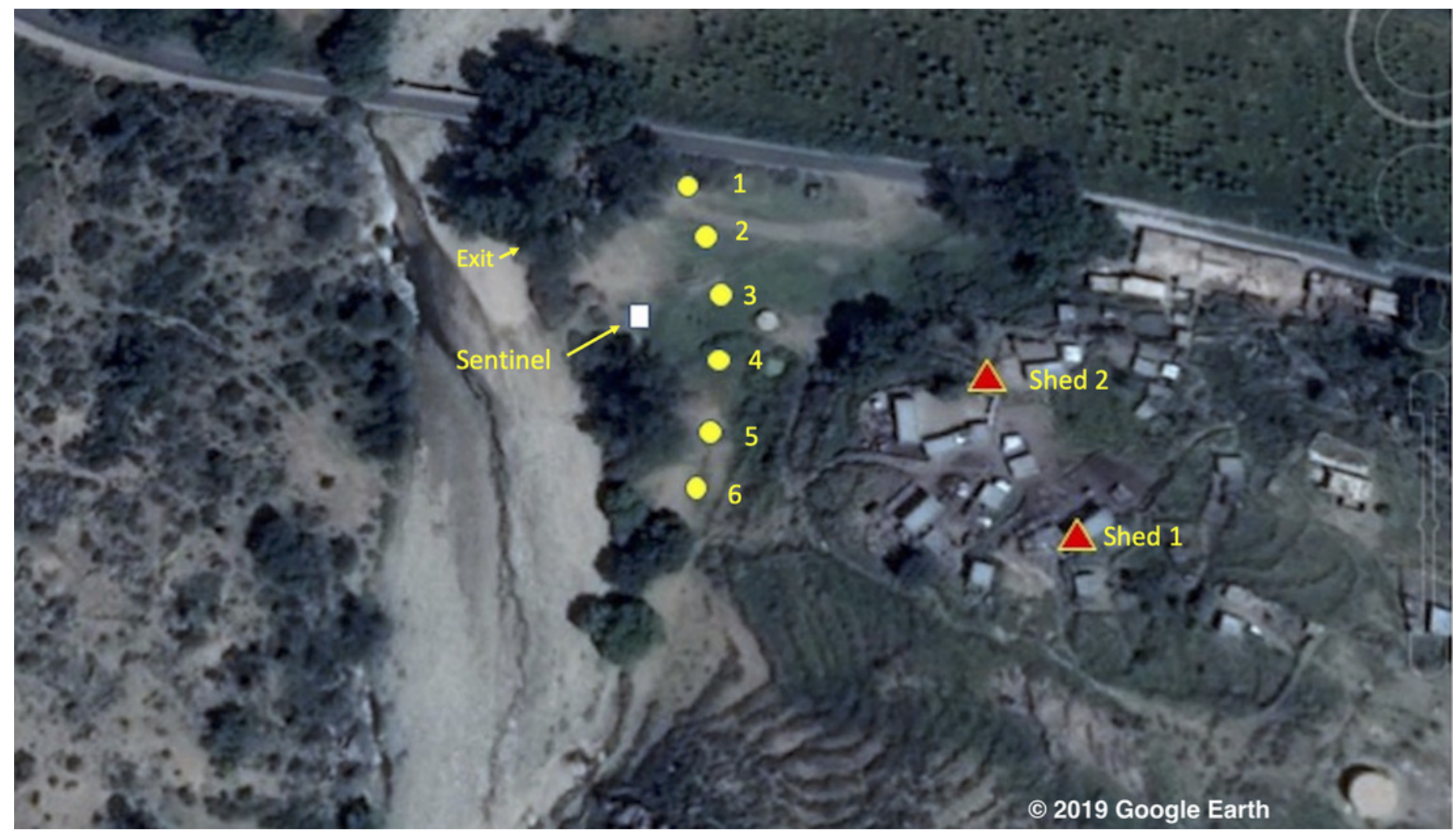


Figure 2

Furvela tent-trap with lure attached

Position of the lure attached below the opening of the Furvela tent-trap. photo $\subset$ JD Charlwood

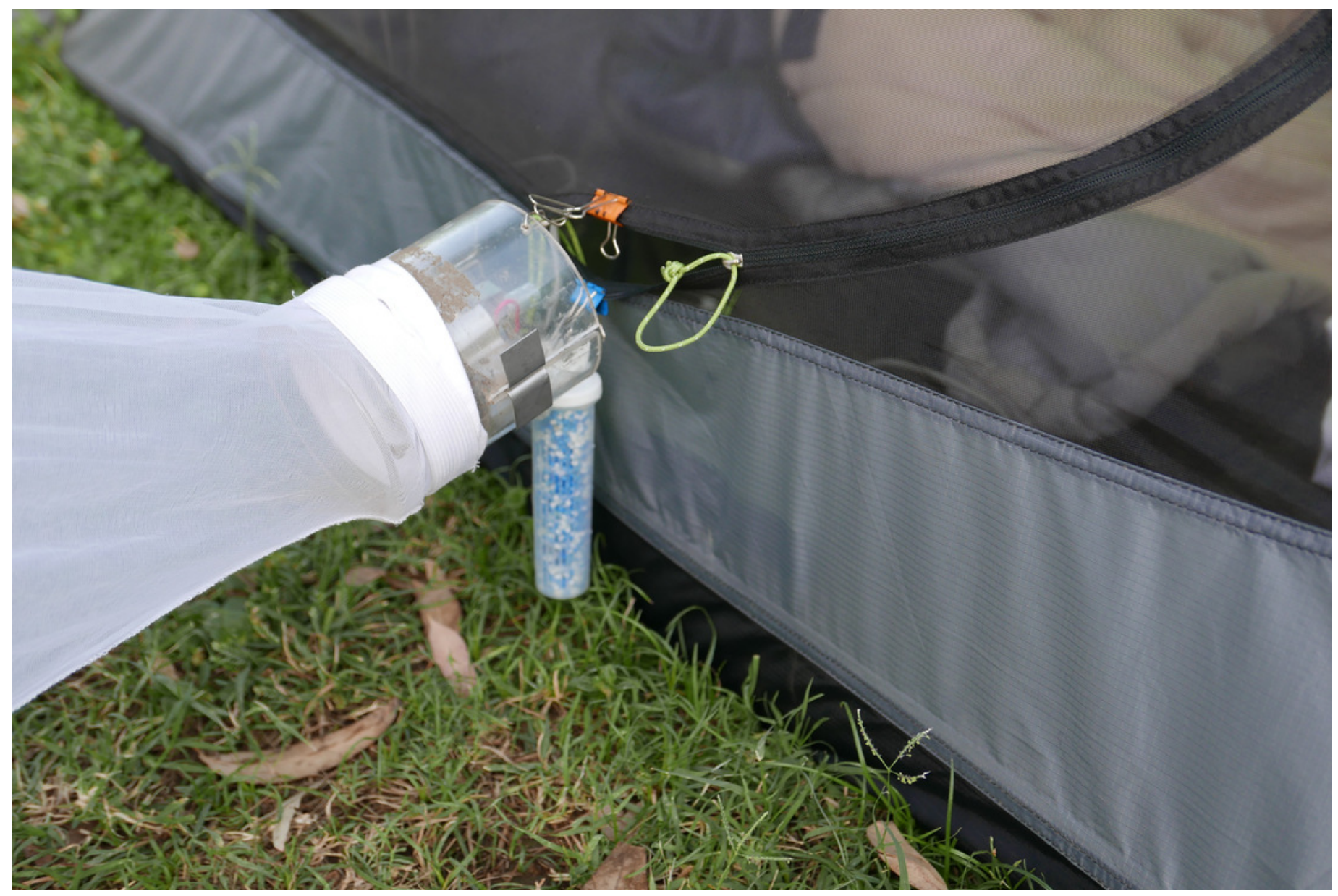




\section{Figure 3}

Furvela tent-trap type II

Close up of the attachment of the CDC trap body to the tent type II trap. A - plywood board with circular opening equivalent to the size of the CDC trap, B - L-shaped supports for the CDC trap, C - CDC trap body with light and grid removed, D - Tent with zip open to allow odor and carbon dioxide easy egress. Photo @ JD Charlwood

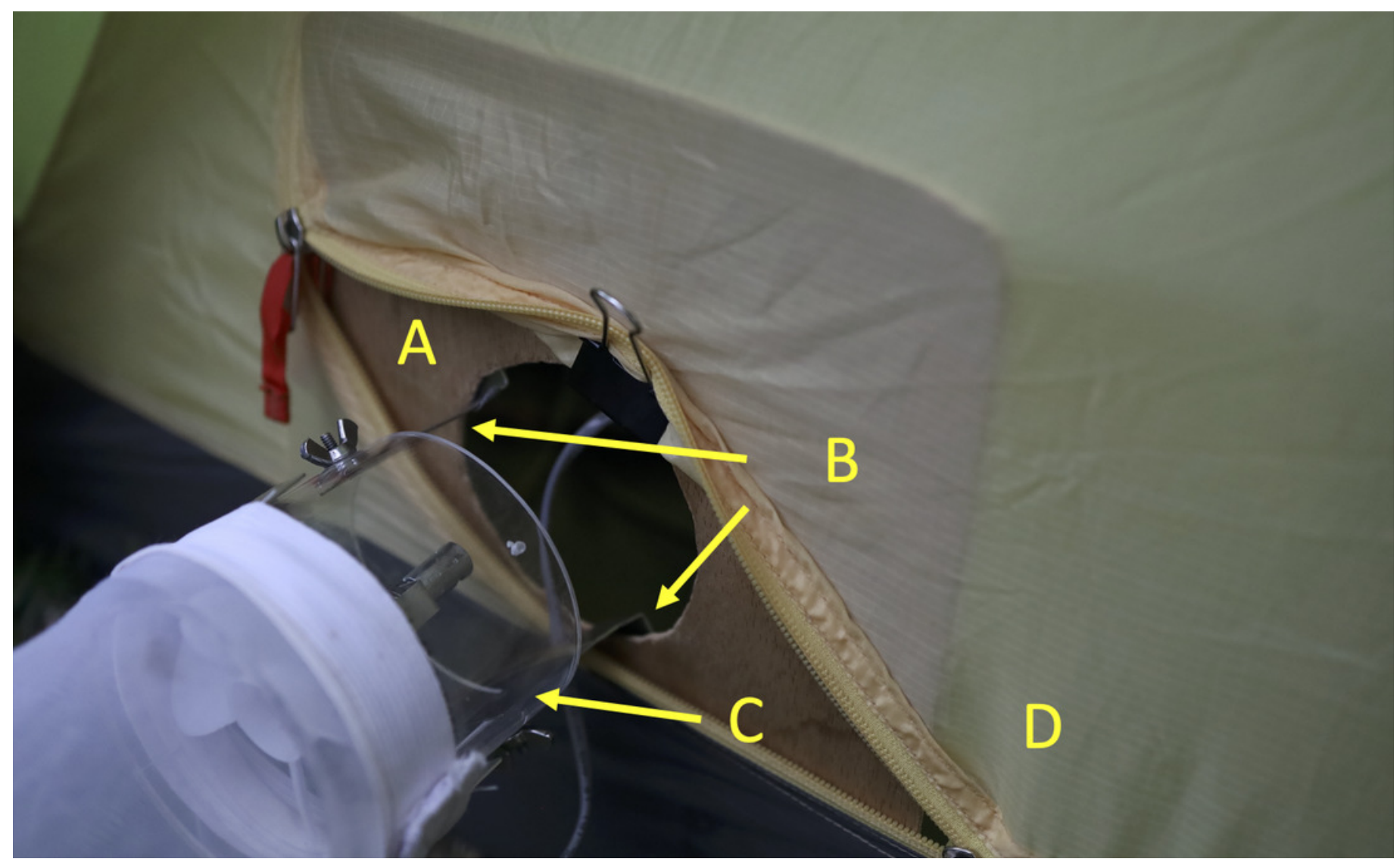




\section{Figure 4}

Suna trap with carbon dioxide

Suna trap in situ in an area close to Adi Boskal. A - Tripod supporting the trap, B - Trap cover, C - Trap inlet, D - 12 volt lead/acid battery powering the trap, E - 5 litre bottle containing the sugar/yeast mix used to generate carbon dioxide, F - Overflow bottle. An artificial lure is also

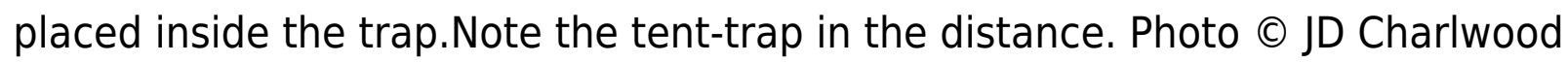




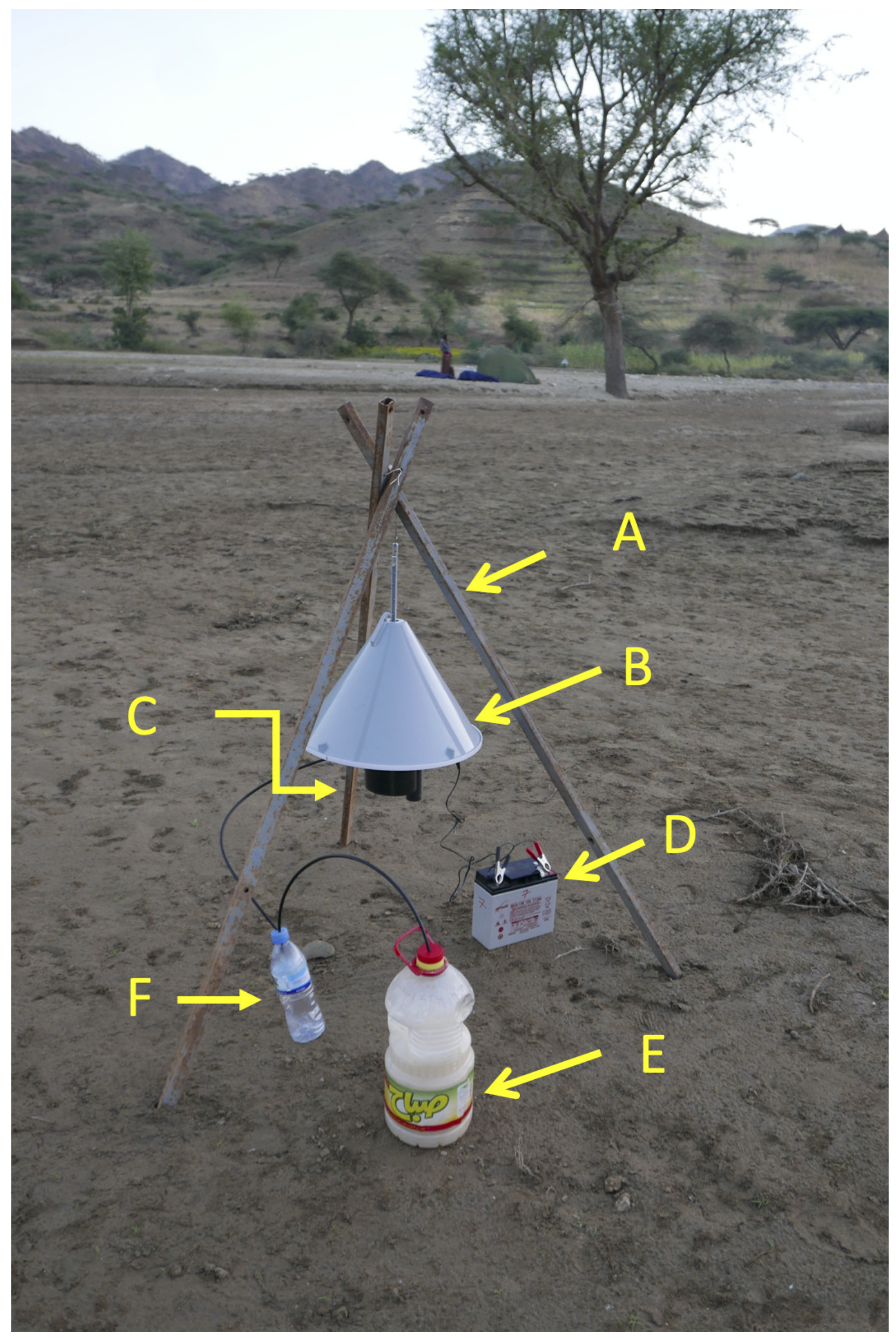




\section{Figure 5}

Set up of mosquito net over vegetation for use in the collection of mosquitoes leaving diurnal resting at dusk

(A) Double sized mosquito net placed horizontally over opening in vegetation, (B) Material used to cover any excess openings, (C) Pole to support net in place.

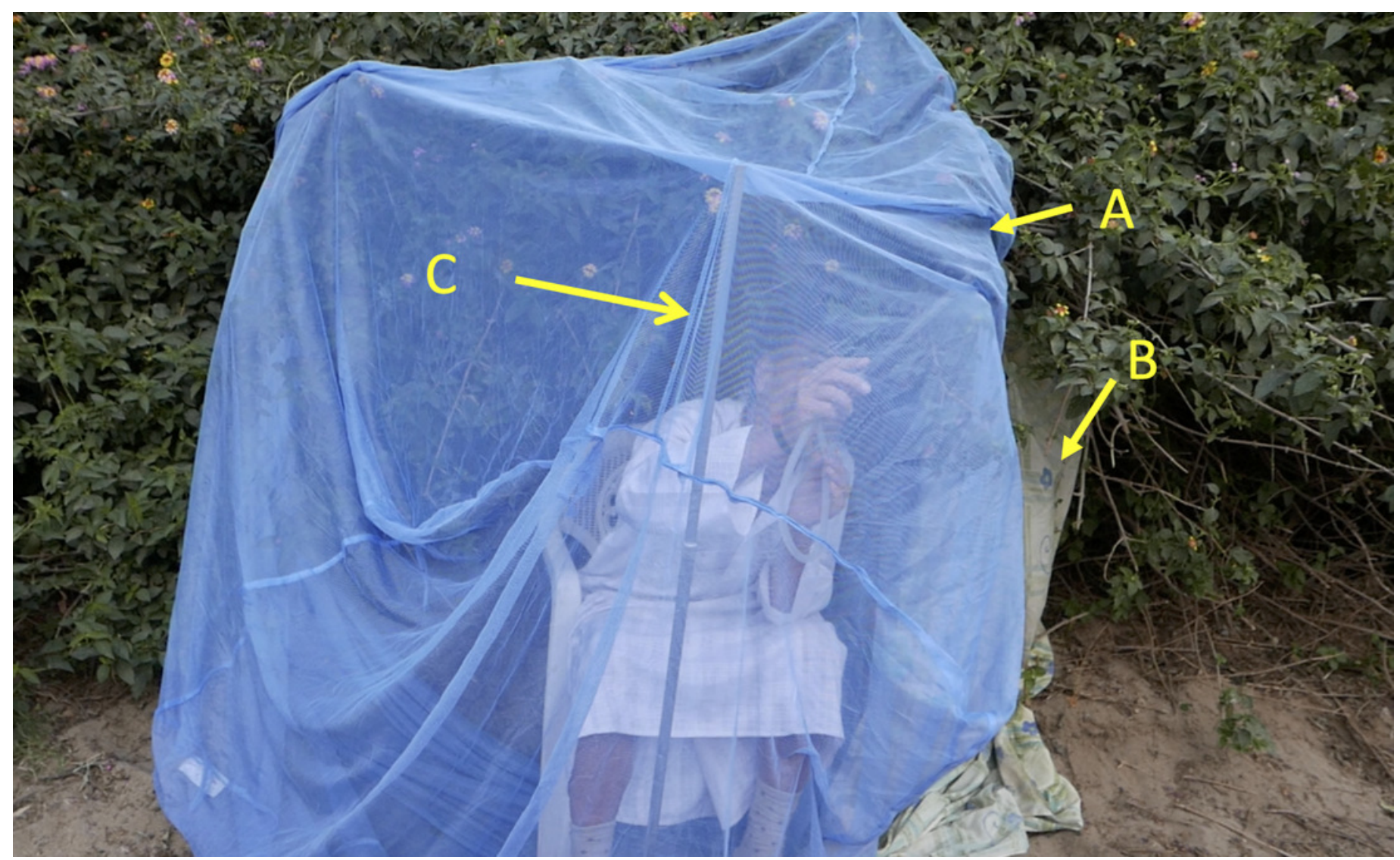


Figure 6

Daigram of mosquito abdomens at different stages of gonotrophic development

A) unfed, no blood or developing eggs visible; B) Engorged, abdomen full of fresh blood; C)

Semi-gravid, anterior half of abdomen with dark blood and posterior half showing developing eggs; D) Gravid, abdomen full of eggs (Redrawn from Gillies et al., 1961)

A
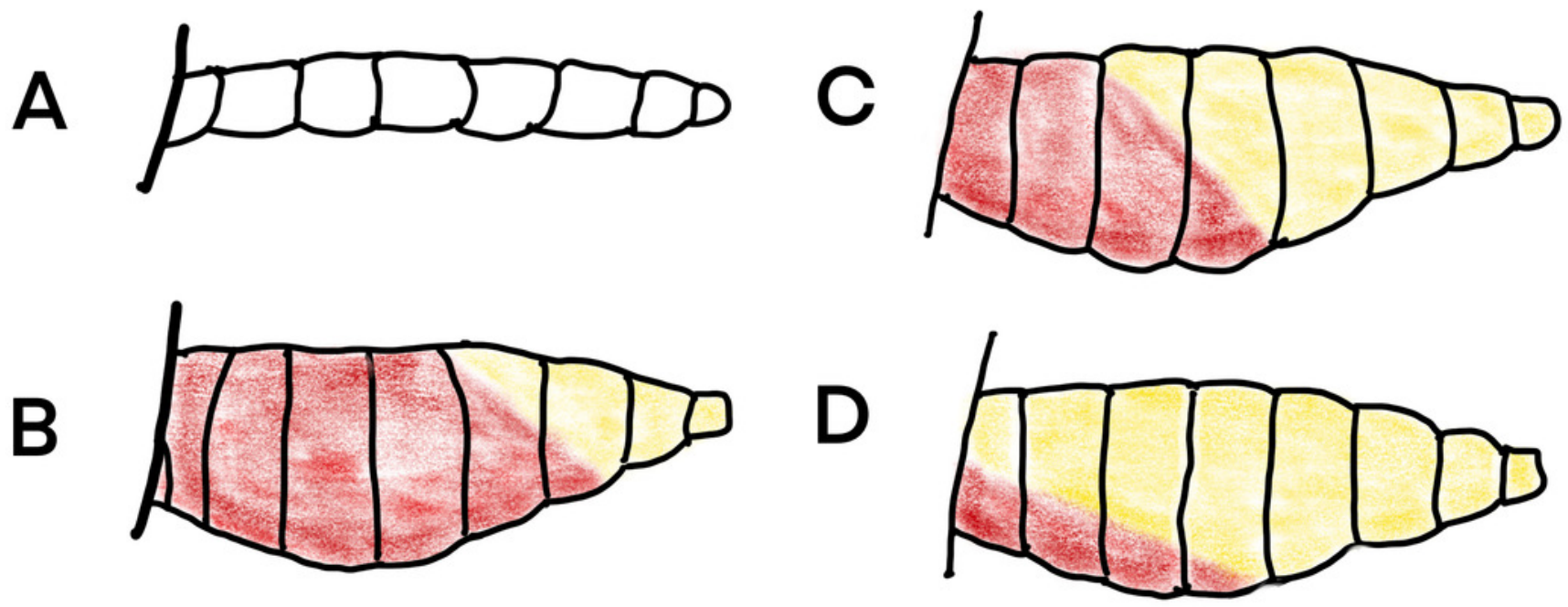
Figure 7

Tent traps and parous rates

Mean number of Anopheles arabiensis collected in experimental tent traps (on a log scale) and proportion of the collection that was parous by date of collection, Adi Boskal, Anseba zoba, Eritrea.

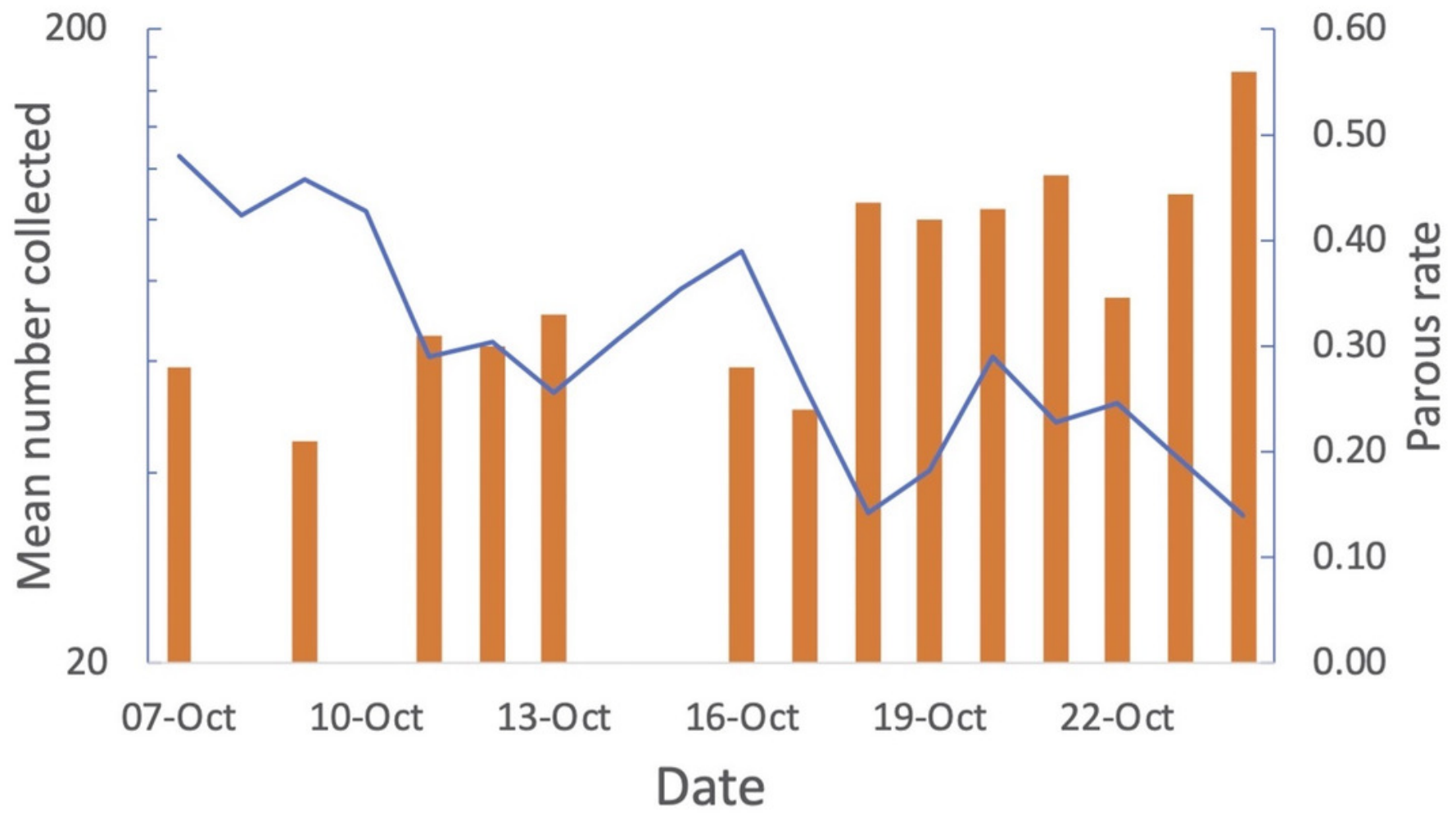


Figure 8

Resting collections of Anopheles arabiensis

Relationship between collection methods, shed and sampling round on numbers of Anopheles arabiensis caught resting, Adi Boskal, Eritrea. (A) Shed 2, Round 1 (B) Shed 2, Round 2. (C) Shed 2 Round 3. (D) Shed 2 Round 4. (E) Shed 2 Round 5. (F) Shed 1 Round 1. (G) Shed 1 Round 2. (H) Shed 1 Round 3. (I) Shed 1 Round 4. (J) Shed 1 Round 5. In each box the method used from left to right was Manual aspirator, Backpack aspirator and Procopack aspirator.

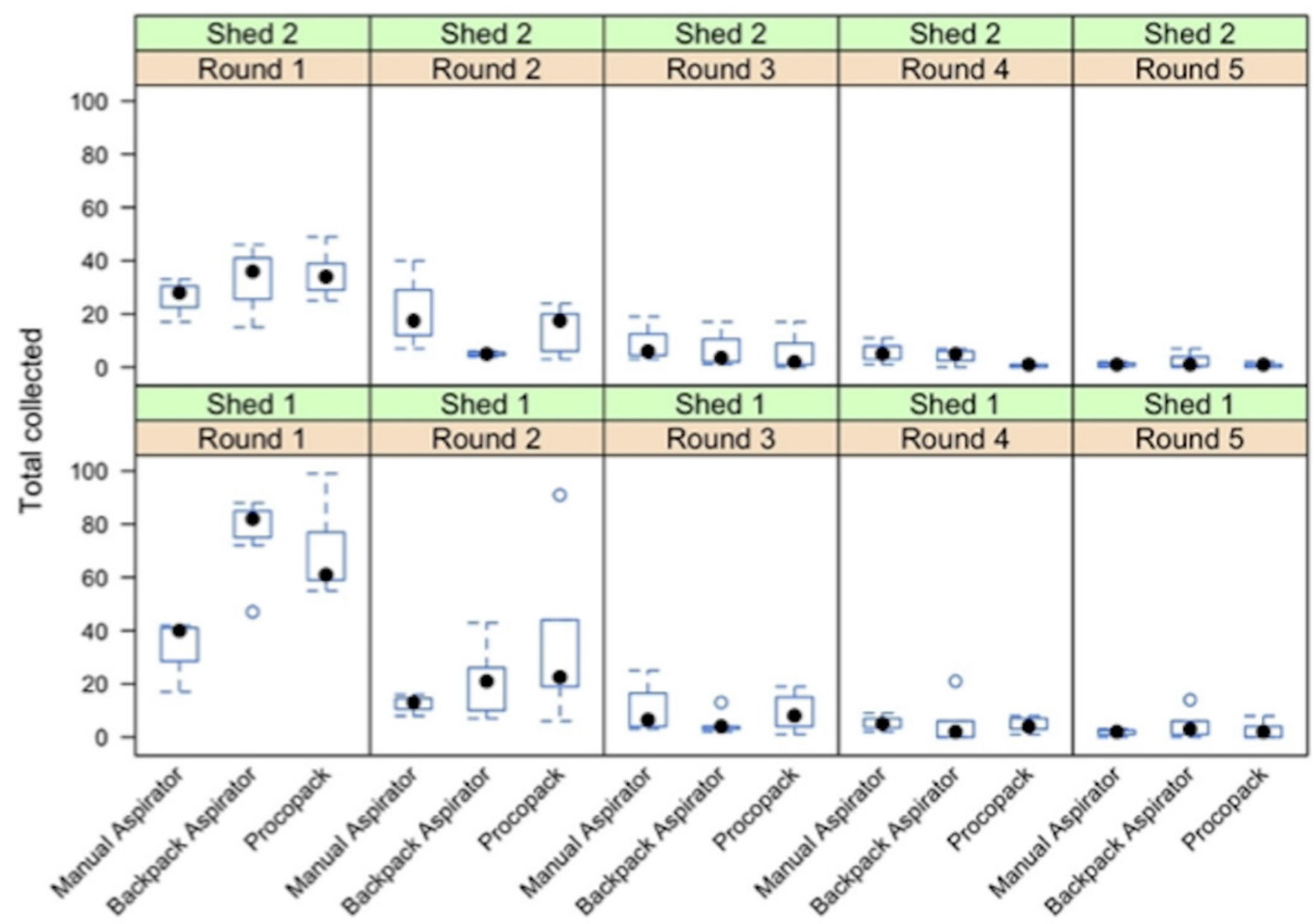


Figure 9

Comparison between sampling techniques for indoor resting mosquitoes

Performance of Backpack and Prokopack sampling indoor resting Anopheles arabiensis compared to manual aspiration (reference), Adi Boskal, Eritrea 


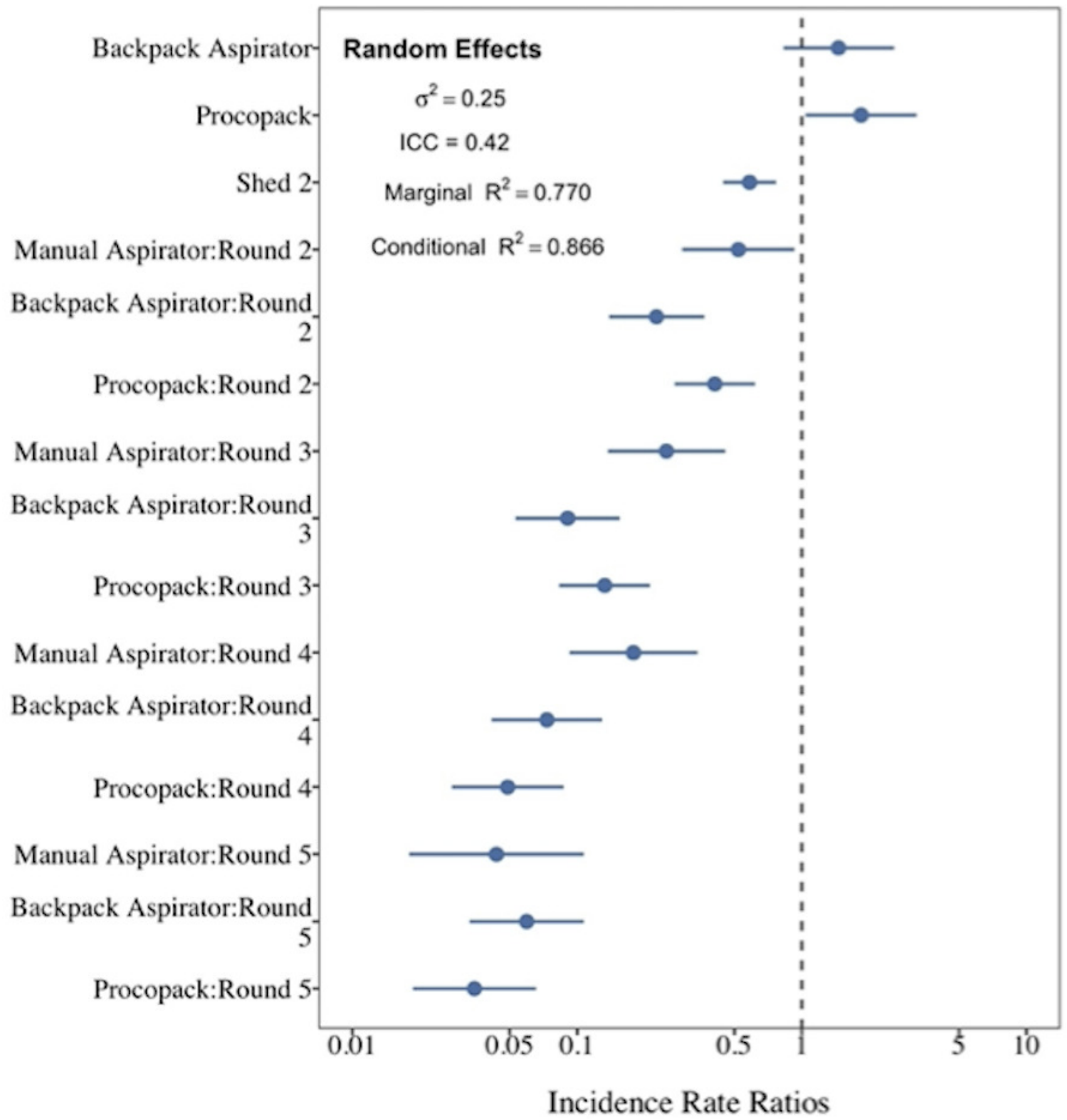


Figure 10

Collection of mosquitoes exiting vegetation at sunset

Numbers of male, unfed female and gravid female Anopheles arabiensis exiting vegetation according to light-level, Adi Boskal, Eritrea.

80

1000

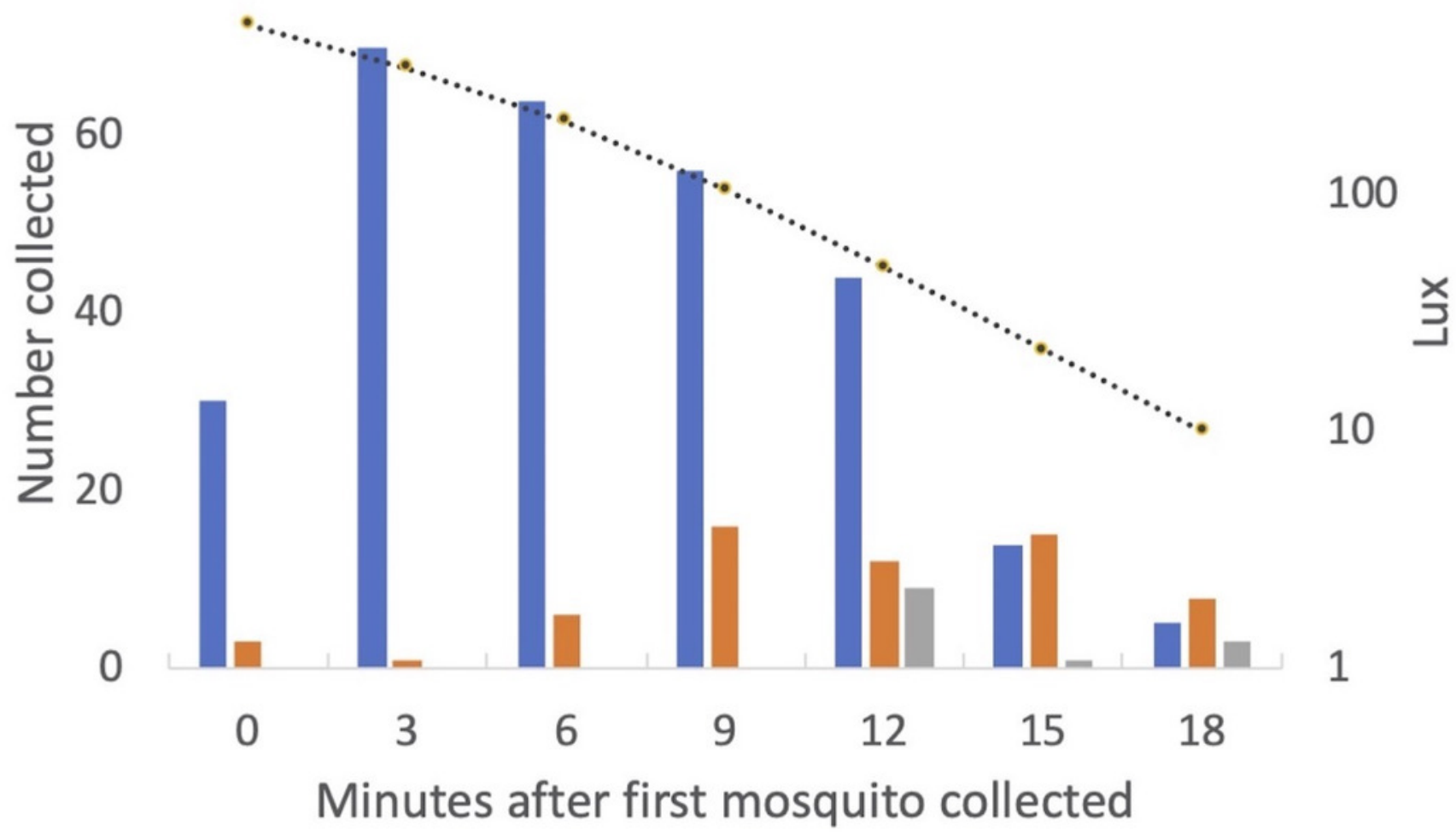

male unfed female gravid female ...... Light 
Figure 11

Comparison between collection methods of host seeking mosquitoes.

Density of host-seeking Anopheles arabiensis obtained by different sampling methods in Adi Boskal, Eritrea

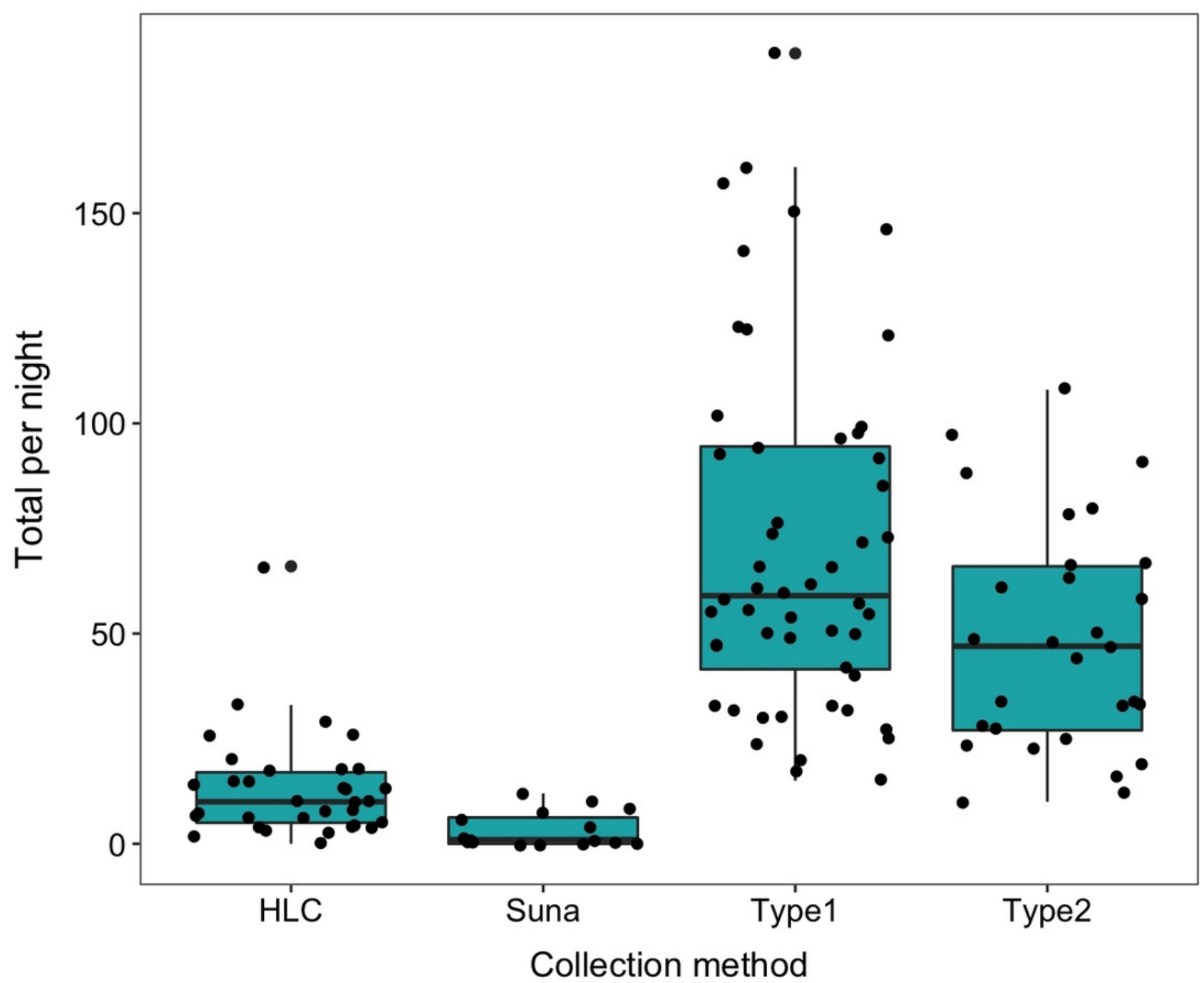




\section{Table $\mathbf{1}$ (on next page)}

Comparison of abundance of An. arabiensis found resting indoors at site 1 and site 2 estimated by removal sampling. $\mathrm{N}$ : Estimated total abundance and $\mathrm{p}$ : probability of mosquito collection 


\begin{tabular}{|c|c|c|c|c|c|c|c|c|c|}
\hline \multirow[b]{2}{*}{ Method } & \multirow[b]{2}{*}{ Parameter } & \multicolumn{4}{|c|}{ Shed 1} & \multicolumn{4}{|c|}{ Shed 2} \\
\hline & & & $\mathbf{S E}$ & $95 \% \mathrm{CI}$ & $\begin{array}{l}\text { Proportion } \\
\text { in round } 1\end{array}$ & & $\mathbf{S E}$ & $95 \% \mathrm{CI}$ & $\begin{array}{l}\text { Proportion in } \\
\text { round } 1\end{array}$ \\
\hline \multirow{3}{*}{$\begin{array}{l}\text { Manual } \\
\text { Aspirator }\end{array}$} & Total & 100 & & & 0.34 & 165 & & & 0.25 \\
\hline & Estimate & 207 & 4.42 & $198.33-215.67$ & & 218 & 4.77 & $208.65-227.35$ & \\
\hline & $\mathrm{p}$ & 0.46 & 0.03 & $0.39-0.53$ & & 0.45 & 0.03 & $0.39-0.52$ & \\
\hline \multirow{3}{*}{ Backpack } & Total & 382 & & & 0.67 & 56 & & & 0.34 \\
\hline & Estimate & 725 & 1.78 & $721.52-728.48$ & & 161 & 2.85 & $155.41-166.59$ & \\
\hline & $\mathrm{p}$ & 0.67 & 0.02 & $0.64-0.70$ & & 0.51 & 0.04 & $0.43-0.58$ & \\
\hline \multirow{3}{*}{ Procopack } & Total & 318 & & & 0.54 & 302 & & & 0.59 \\
\hline & Estimate & 648 & 3.43 & $641.27-654.73$ & & 371 & 1.27 & $368.51-373.49$ & \\
\hline & $\mathrm{p}$ & 0.58 & 0.02 & $0.55-0.61$ & & 0.67 & 0.02 & $0.63-0.71$ & \\
\hline
\end{tabular}




\section{Table 2 (on next page)}

Mean number of $A n$. arabiensis collected from two animal sheds when collections had or had not been made the previous day, Adi Boskal, Anseba zoba, Eritrea. (UF - unfed, PF part-fed, BF - blood-fed, SG - semi-gravid, GR - gravid). 
1

$\begin{array}{lllll}\text { UF } & \text { PF } & \text { BF } & \text { SG } & \text { GR }\end{array}$

$\%$, [95\% C.I.] \%, [95\% C.I.] $\%$, [95\% C.I.] $\quad \%$, [95\% C.I.] $\%$, [95\% C.I.]

No Previous

Collection

Total Shed 1

Total Shed 210

26

189

80

145

Shed 1

$0.9,[0.02,1.8] 5.9,[3.7,8.0]$

126

44

34

Shed 2 $4.0,[1.6,6.5] \quad 14.1,[9.7,18.4]$

$42.6,[38.0,47.2]$

18.0,[14.4, 21.6] 32.7,[28.3,37.0]

Previous $50.6,[44.4,56.8]$

$17.7,[12.9,22.4] \quad 13.7,[9.4,17.9]$

\section{Collection}

Total Shed 1

Total Shed 2

$19 \quad 36$

$36 \quad 167$

167
131

79

55

Shed 1

$5.3,[3.0,7.7] \quad 10.1,[7.0,13.2]$

41

$41 \quad 45$

Shed 2 $5.5,[2.8,8.2] \quad 15.3,[11.1,19.6]$

$46.9,[41.7,52.1]$

$22.2,[17.9,26.5]$

$15.0,[10.7,19.2] \quad 16.4,[12.0,17.9]$ 2 


\section{Table 3(on next page)}

Number of collections, total collected geometric mean number per collection and standard deviation of An. arabiensis collected host seeking, Adi Boskal, Anseba zoba, Eritrea. 


\begin{tabular}{llllll}
\hline Collection & HLC & Tent & Sentinel & Suna with $\mathrm{CO}_{2}$ & Suna without $\mathrm{CO}_{2}$ \\
\hline$n$ & 8 & 19 & 30 & 8 & 8 \\
Total collected & 296 & 1248 & 2107 & 40 & 10 \\
Geometric Mean & 35.0 & 72.4 & 162.2 & 3.1 & 0.6 \\
S.D. & 12.9 & 19.3 & 45.7 & 4.6 & 2.7 \\
\hline
\end{tabular}

1 